Article

\title{
Post-Traumatic Sepsis Is Associated with Increased C5a and Decreased TAFI Levels
}

\author{
Jan Tilmann Vollrath ${ }^{1}$, Ingo Marzi ${ }^{1}$, Anna Herminghaus ${ }^{2}$, Thomas Lustenberger ${ }^{1}$ and \\ Borna Relja 1,3,* \\ 1 Department of Trauma, Hand and Reconstructive Surgery, Goethe University, 60590 Frankfurt, Germany; \\ Tilmann.Vollrath@kgu.de (J.T.V.); Ingo.Marzi@kgu.de (I.M.); Thomas.Lustenberger@kgu.de (T.L.) \\ 2 Department of Anesthesiology, Duesseldorf University Hospital, 40225 Duesseldorf, Germany; \\ Anna.Herminghaus@med.uni-duesseldorf.de \\ 3 Experimental Radiology, Department of Radiology and Nuclear Medicine, Otto von Guericke University, \\ 39120 Magdeburg, Germany \\ * Correspondence: Borna.Relja@med.ovgu.de; Tel.: +49-391-67-282-42
}

Received: 8 March 2020; Accepted: 20 April 2020; Published: 24 April 2020

\begin{abstract}
Background: Sepsis frequently occurs after major trauma and is closely associated with dysregulations in the inflammatory/complement and coagulation system. Thrombin-activatable fibrinolysis inhibitor (TAFI) plays a dual role as an anti-fibrinolytic and anti-inflammatory factor by downregulating complement anaphylatoxin $\mathrm{C} 5 \mathrm{a}$. The purpose of this study was to investigate the association between TAFI and C5a levels and the development of post-traumatic sepsis. Furthermore, the predictive potential of both TAFI and C5a to indicate sepsis occurrence in polytraumatized patients was assessed. Methods: Upon admission to the emergency department (ED) and daily for the subsequent ten days, circulating levels of TAFI and C5a were determined in 48 severely injured trauma patients (injury severity score (ISS) $\geq 16$ ). Frequency matching according to the ISS in septic vs. non-septic patients was performed. Trauma and physiologic characteristics, as well as outcomes, were assessed. Statistical correlation analyses and cut-off values for predicting sepsis were calculated. Results: Fourteen patients developed sepsis, while 34 patients did not show any signs of sepsis (no sepsis). Overall injury severity, as well as demographic parameters, were comparable between both groups (ISS: $25.78 \pm 2.36$ no sepsis vs. $23.46 \pm 2.79$ sepsis). Septic patients had significantly increased C5a levels (21.62 \pm 3.14 vs. $13.40 \pm 1.29 \mathrm{ng} / \mathrm{mL} ; p<0.05)$ and reduced TAFI levels upon admission to the $\mathrm{ED}(40,951 \pm 5637$ vs. $61,865 \pm 4370 \mathrm{ng} / \mathrm{mL} ; p<0.05)$ compared to the no sepsis group. Negative correlations between TAFI and C5a $(p=0.0104)$ and TAFI and lactate $(p=0.0423)$ and positive correlations between C5a and lactate $(p=0.0173)$, as well as C5a and the respiratory rate $(p=0.0266)$, were found. In addition, correlation analyses of both TAFI and C5a with the sequential (sepsis-related) organ failure assessment (SOFA) score have confirmed their potential as early sepsis biomarkers. Cut-off values for predicting sepsis were $54,857 \mathrm{ng} / \mathrm{mL}$ for TAFI with an area under the curve (AUC) of $0.7550(p=0.032)$ and $17 \mathrm{ng} / \mathrm{mL}$ for C5a with an AUC of $0.7286(p=0.034)$. Conclusion: The development of sepsis is associated with early decreased TAFI and increased C5a levels after major trauma. Both elevated C5a and decreased TAFI may serve as promising predictive factors for the development of sepsis after polytrauma.
\end{abstract}

Keywords: polytrauma; sepsis; complement; patients

\section{Introduction}

Trauma is responsible for one out of 10 deaths worldwide and is among the most frequent causes of mortality, notably among young people [1]. Traumatized patients who survive the initial post-injury 
phase are at high risk to die from late-occurring complications such as multiple organ failure (MOF), respiratory complications, and/or sepsis [2-5]. During sepsis, the activation of both coagulation and complement systems, which can be triggered by a pathogen itself or damaged tissues, is essential as a reaction to tissue injury and for an adequate host defense against pathogens [6,7]. Nevertheless, abnormalities in the well-regulated interactions between these systems or their excessive activation can be harmful and lead to thrombosis or disseminated intravascular coagulation [6,7].

Thrombin-activatable fibrinolysis inhibitor (TAFI), a procarboxypeptidase 2 or carboxypeptidase $\mathrm{U}$, is a carboxypeptidase B-like proenzyme with a molecular weight of $56 \mathrm{kDa}$ [8]. Upon activation by the thrombin-thrombomodulin complex at the vascular endothelial surface, its activated TAFI form (TAFIa) inhibits fibrinolysis by removing C-terminal lysines from fibrin, which are imperative for the efficient formation of plasmin [8,9]. In a septic rat model with Pseudomonas aeruginosa, the inhibition of TAFIa reduced the systemic inflammatory response, thus suggesting that TAFI plays an important role in the deterioration of organ dysfunction in sepsis [10]. In a rat model of a sepsis-complicating burn injury, TAFI was elevated after 24 and $72 \mathrm{~h}$, confirming the close link between inflammation and coagulation [11]. Septic patients, as well as healthy study subjects with low-grade lipopolysaccharide (LPS)-induced endotoxemia, showed decreased levels of TAFI [12,13], and in polytraumatized patients, TAFI levels inversely correlated with the inflammation-associated development of complications [14].

Anaphylatoxin C5a is a strong chemoattractant signal that is involved in the regulation of the innate immune system, playing a key role in host homeostasis, inflammation, and defense against pathogens [15-19]. Upon activation through the cleavage of $C 5$ to $C 5 a$ and $C 5 b$ by the C5-convertase, C5a takes part in the recruitment and activation of inflammatory cells like neutrophils, eosinophils, $\mathrm{T}$ lymphocytes, and monocytes $[19,20]$. Recently, in a baboon model of Escherichia coli bacteremia, it was shown that complement-mediated bacteriolysis had a detrimental effect by inducing a release of LPS and fulminant inflammation [21]. The inhibition of C5 cleavage blocked sepsis-induced inflammation, decreased the associated consumptive coagulopathy, and protected organ functions, resulting in improved survival [21].

Besides its role in coagulation, TAFI has been shown to have anti-inflammatory properties, thus being able to inactivate activated complement factors $\mathrm{C} 3 \mathrm{a}$ and $\mathrm{C} 5 \mathrm{a}[22,23]$. Therefore, in the present study, we included severely injured trauma patients with sepsis to determine whether TAFI might represent a possible link between inflammation/complement and coagulation in sepsis.

\section{Materials and Methods}

\subsection{Ethics}

This study was performed at the University Hospital of the Goethe University Frankfurt with the institutional ethical approval in accordance with the Declaration of Helsinki and following the Strengthening the Reporting of Observational Studies in Epidemiology (STROBE) guidelines (167/05). Written informed consent was obtained from all enrolled patients in accordance with ethical standards. All patients signed the informed consent forms themselves, or informed consent was obtained from the nominated legally authorized representative consenting on the behalf of participants, as approved by the ethical committee.

\subsection{Patients}

Patients were included according to the following criteria: history of penetrating or blunt trauma with an injury severity score (ISS) $\geq 16$ and between 18 and 80 years of age. Patients with pre-existing immunological disorders, concomitant acute myocardial infarction, immunosuppressive or anticoagulant medication, burns, thromboembolic events, and/or lethal injury were excluded. All patients were treated according to the Advanced Trauma Life Support (ATLS ${ }^{\circledR}$ ) standards and the polytrauma guidelines. While haemodynamically instable patients received immediate surgery, haemodynamically stable patient underwent whole-body computed tomography. Upon arrival to 
the emergency room, the following demographic and clinical data were collected: age; gender; blood pressure; respiratory rate; heart rate; temperature; mechanism of injury; abbreviated injury scale for each body region (head, chest, abdomen, and extremity); and the general injury severity (ISS), as described before [24]. Routine blood gas analysis (including $\mathrm{pH}$ and lactate) was performed upon admission to the hospital. The numbers of fresh frozen plasma (FFP) and packed red blood cell (PRBC) units transfused within the first $24 \mathrm{~h}$ and during further clinical course were recorded. The diagnose of sepsis was assessed by both the 2005 criteria outlined by the International Sepsis Forum [25], as well as by the revised definition criteria according to the Sepsis-3 criteria [26,27]. Systemic inflammatory response syndrome (SIRS) was defined by fulfilling at least two of the following criteria: heart rate $>90$ beats per minute, respiratory rate $>20$ per minute or arterial carbon dioxide tension $\left(\mathrm{PaCO}_{2}\right)<32 \mathrm{~mm} \mathrm{Hg}$, body temperature $>38^{\circ} \mathrm{C}$ or $<36{ }^{\circ} \mathrm{C}$, and white blood cell count $>12,000$ cells $/ \mathrm{mm}^{3}$ or $<4000$ cells $/ \mathrm{mm}^{3}$ or with $>10 \%$ immature forms. According to the old definition, sepsis was diagnosed when the patients fulfilled criteria for SIRS and had evidence for an infection. However, limitations of that definition, including an excessive focus on inflammation and the inadequate specificity and sensitivity of the SIRS criteria, led to the Sepsis-3 definition, in which sepsis was defined as life-threatening organ dysfunction caused by a dysregulated host response to infection. The authors have summarized that, for clinical operationalization, organ dysfunction can be represented by an increase in the sequential (sepsis-related) organ failure assessment (SOFA) score of 2 points or more, which is associated with an enhanced in-hospital mortality risk $[26,27]$. Medical records were analyzed regarding length of in-hospital stay, length of ICU stay, and in-hospital mortality.

\subsection{Blood Processing and Analysis}

Blood samples were obtained from 48 severely traumatized patients as early as possible after admission to the emergency department (ED) and until day ten daily in pre-chilled ethylene-diaminetetraacetic acid (EDTA) or heparin vacuum tubes (BD vacutainer; Becton Dickinson Diagnostics, Aalst, Belgium) for routine diagnostics or for laboratory investigations and were kept on ice until centrifugation at $2000 \times \mathrm{g}$ for $15 \mathrm{~min}$ at $4{ }^{\circ} \mathrm{C}$. Afterwards, supernatants were stored at $-80^{\circ} \mathrm{C}$ until analysis. The mean time between injury and acquisition of the blood sample was $81 \pm 8 \mathrm{~min}$.

TAFI levels were measured by using a commercially available ELISA (IMUCLONETM TAFI ELISA; American Diagnostica Inc., Stamford, CT, USA) according to the manufacturer's instructions. The TAFI antigen level is expressed as a percentage of normal pooled plasma. C5a levels were determined using a commercially available Human C5a ELISA kit II (BD Biosciences, Heidelberg, Germany) according to the manufacturer's instructions. Blood counts were measured using the Sysmex XE-2100 automated blood cell counter (Sysmex Europe $\mathrm{GmbH}$, Norderstedt, Germany). pH, lactate, and $\mathrm{PaCO}_{2}$ were determined using a standard clinical blood gas analysis device (ABL800 Flex, Radiometer, Krefeld, Germany).

\subsection{Statistics}

All data were tested for normal distribution by a Kolmogorov-Smirnov-Lillieford's test. Continuous variables were compared using the Mann-Whitney U test, and categorical variables were analyzed with the two-sided Fisher's exact test. Data are presented as the mean \pm standard error of the mean (SEM) unless otherwise stated. Receiver-operator curves (ROC) were calculated to analyze the optimal cut-off values. The sample size was performed based on the mean TAFI data obtained from the pilot study in Relja et al. [14]. Based on the mean values, a Cohen's d of 1.060 and an effect size of $r=0.468$ were calculated. Applying a power of 0.8 , a group size of 15 per group is necessary to reach significant results in an unpaired $t$-test $(\alpha=0.05)$. Results were considered as statistically significant when the $p$-value was $<0.05$. Statistical analysis was performed using GraphPad Prism 5.0 software (GraphPad Software Inc., San Diego, CA, USA). 


\section{Results}

\section{Main Findings}

A cohort of 48 patients (33 male) met the inclusion criteria and were included in the study. Mean patient age was $52.23 \pm 2.74$ years, and all patients were substantially injured with a mean ISS of $24.95 \pm 1.75$. Of these, 14 patients with an ISS of $23.36 \pm 2.79$ developed sepsis during the clinical course, while 34 patients with an ISS of $25.78 \pm 2.36$ did not develop sepsis or septic complications. Table 1 summarizes the general patient and injury characteristics of the study population. There were no significant differences between the sepsis and no sepsis group with regard to the general patient and injury characteristics. The mean time between the onset of trauma and arrival to the ED was $66.17 \pm 4.85 \mathrm{~min}$. The mean time until admission to the ED between the cohort of septic patients vs. not septic patients did not statistically differ $(65.40 \pm 11.55$ vs. $66.50 \pm 5.17 \mathrm{~min})$.

Table 1. Demographic and trauma characteristics of the study population. Data are given as mean \pm standard error of the mean; $p<0.05$. Abbreviations: $a$, no sepsis group; AIS, abbreviated injury scale; $b$, sepsis group; ISS, injury severity score; and ns, no significance.

\begin{tabular}{|c|c|c|c|c|}
\hline $\begin{array}{l}\text { Subjects and Trauma } \\
\text { Characteristics }\end{array}$ & $\begin{array}{c}\text { Total } \\
(n=48)\end{array}$ & $\begin{array}{l}\text { No Sepsis } \\
\quad(n=34)\end{array}$ & $\begin{array}{l}\text { Sepsis } b \\
(n=14)\end{array}$ & $\begin{array}{c}p<0.05 \\
\text { a vs. b }\end{array}$ \\
\hline age (years), mean \pm sem & $52.23 \pm 2.74$ & $48.45 \pm 3.74$ & $56,54 \pm 3.68$ & ns \\
\hline gender (male, \%) & $33(68.75 \%)$ & $22(64.71 \%)$ & $11(78.57 \%)$ & ns \\
\hline trauma mechanism (falls) & $23(47.92 \%)$ & $16(47.06 \%)$ & $7(50.00 \%)$ & ns \\
\hline ISS & $24.95 \pm 1.75$ & $25.78 \pm 2.36$ & $23.46 \pm 2.79$ & ns \\
\hline \multicolumn{5}{|l|}{ AIS $\geq 3(n, \%)$} \\
\hline Head & $22(45.83 \%)$ & $16(47.06 \%)$ & $6(42.86 \%)$ & ns \\
\hline Chest & $16(33.33 \%)$ & $11(32.35 \%)$ & $5(35.71 \%)$ & ns \\
\hline Abdomen & $7(14.58 \%)$ & $4(11.76 \%)$ & $3(21.43 \%)$ & ns \\
\hline Extremity & $10(20.83 \%)$ & $7(20.59 \%)$ & $3(21.43 \%)$ & ns \\
\hline
\end{tabular}

To investigate the influence of blood transfusions concerning the development of sepsis after polytrauma, the number of fresh frozen plasma (FFP) and packed red blood cells (PRBC) during the first $24 \mathrm{~h}$ after admittance to the emergency department and during the whole clinical course were determined. Patients belonging to the sepsis group received significantly more units of packed red blood cells during the whole clinical treatment compared to the no sepsis group (10.50 \pm 2.50 vs. $5.46 \pm 21.74 ; p<0.05)$. As depicted in Table 2, there were no significant differences between these two groups concerning the units of packed red blood cells during the first $24 \mathrm{~h}$, the systolic blood pressure $<90 \mathrm{~mm} \mathrm{Hg}$ at admittance to the ED, the number of transfused units of fresh frozen plasma within $24 \mathrm{~h}$ or during the whole clinical course, or the body temperature at admittance to the ED. Furthermore, no significant differences among the groups in the international normalized ratio (INR), activated partial thromboplastin time (PTT), or platelet counts (PLT) were assessed. 
Table 2. Physiologic characteristics of the study population. Data are given as mean \pm standard error of the mean; $p<0.05$. Abbreviations: $a$, no sepsis group; $b$, sepsis group; ED, emergency department; FFP, fresh frozen plasma; INR, international normalized ratio; ns, no significance; PLT, platelet; PRBC, packed red blood cells; PTT, activated partial thromboplastin time; and SBP, systolic blood pressure.

\begin{tabular}{|c|c|c|c|c|}
\hline Physiologic Characteristics & $\begin{array}{c}\text { Total } \\
(n=48)\end{array}$ & $\begin{array}{c}\text { No Sepsis }^{\mathrm{a}} \\
\quad(n=34)\end{array}$ & $\begin{array}{l}\text { Sepsis }^{b} \\
(n=14)\end{array}$ & $\begin{array}{c}p<0.05 \\
\text { a vs. } b\end{array}$ \\
\hline $\mathrm{SBP}<90 \mathrm{~mm} \mathrm{Hg}(\mathrm{ED}, n, \%)$ & $5(10.42 \%)$ & $2(5.71 \%)$ & $3(21.43 \%)$ & ns \\
\hline PRBC transfusion within $24 \mathrm{~h}$ (Units) & $4.84 \pm 1.18$ & $3.81 \pm 1.53$ & $7.14 \pm 2.01$ & ns \\
\hline PRBC transfusion total (Units) & $6.98 \pm 1.41$ & $5.46 \pm 21.74$ & $10.50 \pm 2.50$ & $<0.05$ \\
\hline FFP transfusion within $24 \mathrm{~h}$ (Units) & $2.54 \pm 0.69$ & $1.65 \pm 0.71$ & $4.31 \pm 1.45$ & ns \\
\hline FFP transfusion total (Units) & $2.68 \pm 0.75$ & $1.73 \pm 0.75$ & $4.43 \pm 1.56$ & ns \\
\hline INR (ED) & $1.34 \pm 0.08$ & $1.36 \pm 0.11$ & $1.31 \pm 0.06$ & ns \\
\hline PTT $(E D, s)$ & $36.13 \pm 2.79$ & $37.12 \pm 3.88$ & $33.72 \pm 1.62$ & ns \\
\hline PLT count $\left(\mathrm{ED}, \times 10^{3} / \mu \mathrm{L}\right)$ & $201.40 \pm 10.34$ & $198.00 \pm 12.44$ & $210.30 \pm 18.97$ & ns \\
\hline
\end{tabular}

A significantly prolonged stay in the intensive care unit was observed in septic patients (22.14 \pm 4.12 days vs. $7.00 \pm 1.16 ; p<0.0001)$, and in-hospital stays lasted significantly longer for this group $(41.07 \pm 6.43$ vs. $19 \pm 2.90 ; p<0.001)$ compared to the group without septic complications. A total of six patients $(12.5 \%)$ died, with a significantly higher number of patients in the sepsis group compared with the no sepsis group (four vs. two; $p<0.05$; Table 3 ).

Table 3. Outcome of the study population. Data are given as mean \pm standard error of the mean; $p<$ 0.05. Abbreviations: $a$, no sepsis group; $b$, sepsis group; ICU, intensive care unit.

\begin{tabular}{|c|c|c|c|c|}
\hline Outcome & $\begin{array}{c}\text { Total } \\
(n=48)\end{array}$ & $\begin{array}{l}\text { No Sepsis } \\
\quad(n=34)\end{array}$ & $\begin{array}{l}\text { Sepsis }^{b} \\
(n=14)\end{array}$ & $\begin{array}{c}p<0.05 \\
\text { a vs. b }\end{array}$ \\
\hline ICU stay (days) & $11.71 \pm 1.82$ & $7.00 \pm 1.16$ & $22.14 \pm 4.12$ & $<0.0001$ \\
\hline in-hospital stay (days) & $25.67 \pm 3.13$ & $19.00 \pm 2.90$ & $41.07 \pm 6.43$ & $<0.001$ \\
\hline in-hospital mortality $(n, \%)$ & $6(12.5 \%)$ & $2(5.88 \%)$ & $4(28.57 \%)$ & $<0.05$ \\
\hline
\end{tabular}

In order to further investigate the differences of clinical features at admission to the ED between patients developing sepsis during the clinical course and patients who did not develop sepsis, we compared lactate concentrations and $\mathrm{pH}$ values in the blood, heart rate, and respiratory rate in our study cohort. As shown in Figure 1, patients who developed sepsis had significantly higher amounts of lactate in their blood and a more acidic constellation of their acid bases balance, as depicted by significantly lower $\mathrm{pH}$ values $(p<0.05$; Figure 1A,B). Furthermore, patients who developed sepsis during the clinical course had significant changes of their vital parameters, as they had higher respiratory and heart rates at their admission to the $\mathrm{ED}(p<0.05$; Figure $1 \mathrm{C}, \mathrm{D})$.

In order to investigate changes in coagulation and inflammation, we measured TAFI and C5a levels at admission to the ED. Patients belonging to the sepsis group had significantly lower TAFI levels and significantly higher C5a levels compared to the no sepsis group, as shown in Figure 2A,B, respectively $(p<0.05)$. Moreover, patients from the sepsis group showed significantly increased leukocytes counts compared with the no sepsis group ( $p<0.05$; Figure $2 \mathrm{C})$. 
A

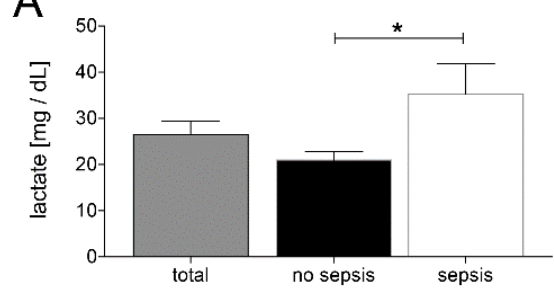

C

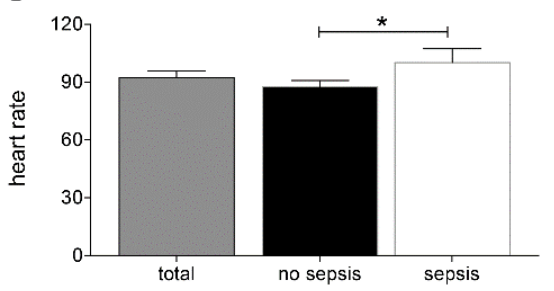

B

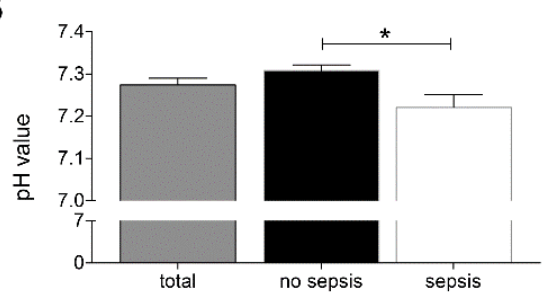

D

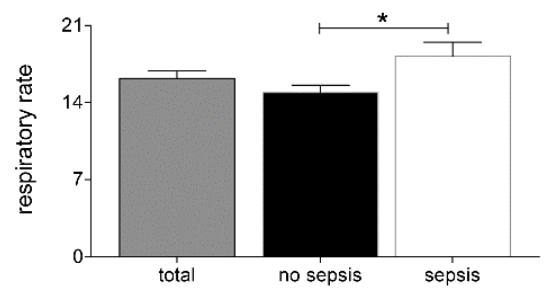

Figure 1. Upon admission of severely injured trauma patients $(n=48)$ to the emergency department, lactate levels (A), pH values (B), heart rate (C), and respiratory rate (D) were measured. Patients were stratified to those who developed sepsis in their clinical course (sepsis, $n=14$ ) vs. those who did not develop infectious complications (no sepsis, $n=34$ ). Data are shown as mean \pm SEM. ${ }^{*} p<0.05$ sepsis vs. no sepsis.

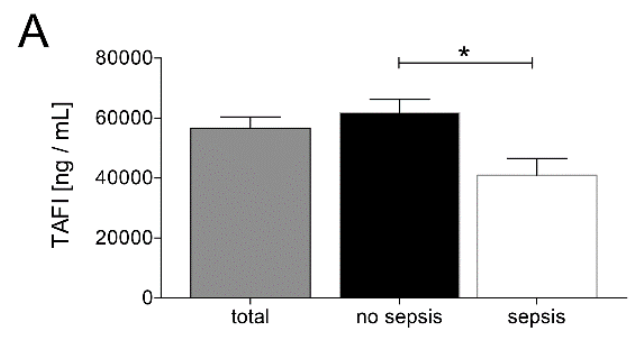

B
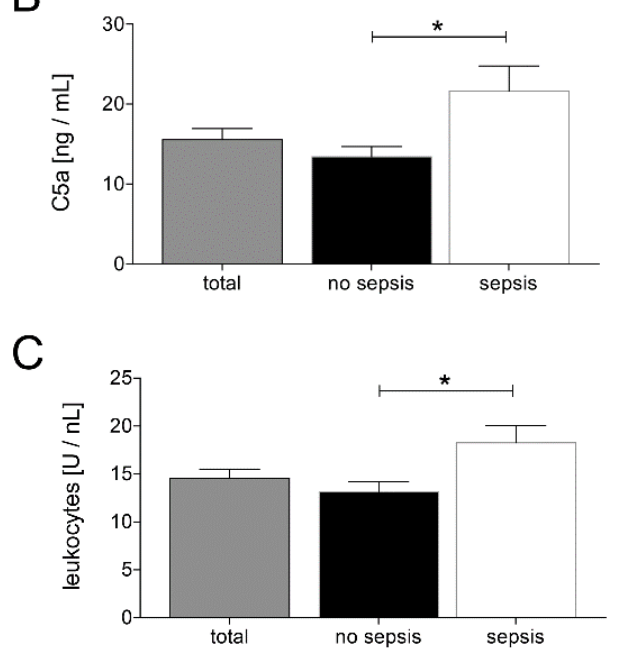

Figure 2. Upon admission of severely injured trauma patients $(n=48)$ to the emergency department, plasma thrombin-activatable fibrinolysis inhibitor (TAFI) levels (A), plasma C5a levels (B), and leukocyte counts $(\mathbf{C})$ were determined. Patients were stratified to those who developed sepsis in their clinical course (sepsis, $n=14$ ) vs. those who did not develop infectious complications (no sepsis, $n=34$ ). Data are shown as mean \pm SEM. ${ }^{*} p<0.05$ sepsis vs. no sepsis.

In addition, we analyzed correlations between TAFI and/or C5a and clinical (heart and respiratory rate) or laboratory parameters ( $\mathrm{pH}$ value, leukocyte count, lactate value, INR, thromboplastin time (TPT), PTT, and PLT) and the SOFA score. TAFI and C5a, as well as TAFI and lactate, have shown a 
significant negative correlation (TAFI and C5a: Pearson $r=-0.4933, p<0.0104$ and TAFI and lactate: Pearson $r=-0.4268, p<0.0423$; Table 4 and Figure 3A,B). Furthermore, C5a and lactate, as well as C5a and the respiratory rate, had a significant correlation ( $\mathrm{C} 5 \mathrm{a}$ and lactate: Pearson $r=0.4542, p<0.0173$ and C5a and respiratory rate: Pearson $r=0.4185, p<0.0266$; Table 4 and Figure 3C,D). In addition, correlation analysis of TAFI and C5a with the SOFA score have shown a significant negative correlation of TAFI with the SOFA score (Pearson $r=-0.3865, p=0.0422$ ) and a significant positive correlation of C5a with the SOFA score (Pearson $r=0.3795, p=0.0386$ ) (Table 4).

Table 4. Correlation analyses between thrombin-activatable fibrinolysis inhibitor (TAFI), C5a, leukocyte counts, lactate levels, $\mathrm{pH}$ values, heart and respiratory rates, sequential (sepsis-related) organ failure assessment (SOFA) score, international normalized ratio (INR), thromboplastin time (TPT), partial thromboplastin time (PTT), and platelet (PLT). $p<0.05$ : statistically significant.

\begin{tabular}{|c|c|c|c|}
\hline Correlation Analysis & Pearson $r$ & $p$-Value & Number of Pairs \\
\hline TAFI and C5a & -0.4933 & 0.0104 & 26 \\
\hline TAFI and leukocytes & -0.2442 & 0.1855 & 31 \\
\hline TAFI and lactate & -0.4268 & 0.0423 & 23 \\
\hline TAFI and pH & 0.2079 & 0.3532 & 22 \\
\hline TAFI and heart rate & -0.2603 & 0.2304 & 23 \\
\hline TAFI and respiratory rate & -0.3685 & 0.0915 & 22 \\
\hline TAFI and SOFA score & -0.3865 & 0.0422 & 28 \\
\hline TAFI and INR & -0.0499 & 0.7860 & 32 \\
\hline TAFI and TPT & 0.0299 & 0.8750 & 30 \\
\hline TAFI and PTT & 0.0369 & 0.8409 & 32 \\
\hline TAFI and PLT & -0.3048 & 0.0085 & 33 \\
\hline C5a and leukocytes & -0.2260 & 0.1918 & 35 \\
\hline C5a and lactate & 0.4542 & 0.0173 & 27 \\
\hline $\mathrm{C} 5 \mathrm{a}$ and $\mathrm{pH}$ & -0.0805 & 0.6839 & 28 \\
\hline $\mathrm{C} 5 \mathrm{a}$ and heart rate & 0.2416 & 0.2068 & 29 \\
\hline C5a and respiratory rate & 0.4185 & 0.0266 & 28 \\
\hline C5a and SOFA score & 0.3795 & 0.0386 & 30 \\
\hline C5a and INR & -0.0199 & 0.9055 & 38 \\
\hline C5a and TPT & -0.2056 & 0.2291 & 36 \\
\hline C5a and PTT & 0.0731 & 0.6629 & 38 \\
\hline C5a and PLT & 0.0138 & 0.9353 & 37 \\
\hline
\end{tabular}

To investigate which of the examined parameters in this study (TAFI, C5a, leukocytes count, lactate, heart rate, and respiratory rate) could provide a prognostic marker for the development of sepsis after polytrauma, the predictive power of each parameter has been calculated using ROC analyses. While the ROC analysis for lactate did not show a statistically significant area under the ROC curve $(p=0.052)$, TAFI showed an optimal cut-off for predicting sepsis on admission to the ED at $54,857 \mathrm{ng} / \mathrm{mL}$, with a sensitivity of $64 \%$ and specificity of $87.50 \%$. The AUC was 0.7550 (95\% CI: 0.585 to $0.925 ; p<0.032$; Table 5 and Figure $4 \mathrm{~A}$ ). C5a showed an optimal cut-off at $17 \mathrm{ng} / \mathrm{mL}$ on admission to the ED for predicting sepsis in the clinical course, with a sensitivity of $75.00 \%$, specificity of $70.00 \%$, and an AUC of 0.7286 (95\% CI: 0.547 to 0.910; $p<0.034$; Table 5 and Figure 4B). Leukocytes showed an optimal cut-off at $14.50 \mathrm{U} / \mathrm{nl}$, with a sensitivity of $65.63 \%$, specificity of $69.23 \%$, and an AUC of 0.7043 (95\% CI: 0.527 to 0.882; $p<0.033$; Table 5 and Figure 4C). The heart rate showed an optimal cut-off 
at 102.5/min on admission to the ED for predicting sepsis in the clinical course, with a sensitivity of 86.96\%, specificity of $64.29 \%$, and an AUC of 0.6957 (95\% CI: 0.490 to 0.902; $p<0.049$; Table 5 and Figure 4E). The respiratory rate showed an optimal cut-off at $15 / \mathrm{min}$, with a sensitivity of $63.64 \%$ and a specificity of $64.29 \%$. The AUC was 0.7029 ( $95 \%$ CI: 0.511 to $0.895 ; p<0.043$; Table 5 and Figure 4F).

A

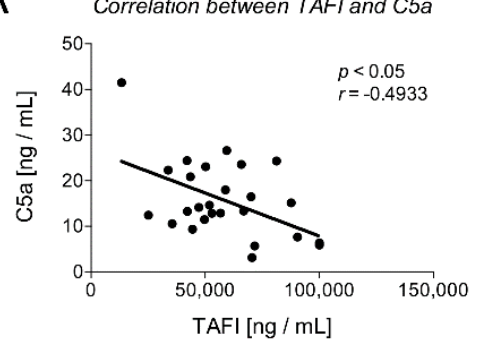

C

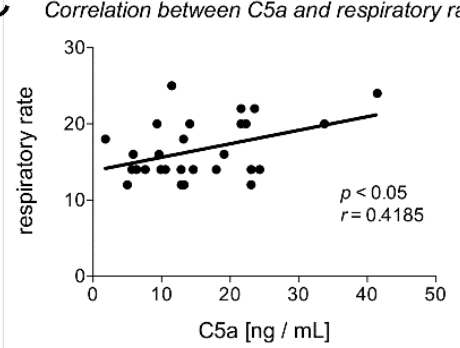

B Correlation between TAFI and lactate

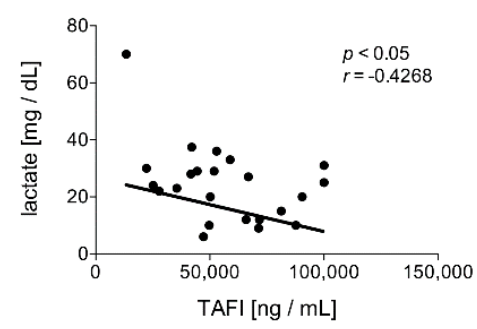

D

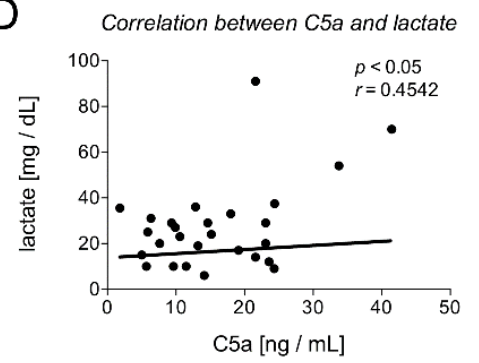

Figure 3. Correlation analysis between TAFI and C5a (A), TAFI and lactate (B), C5a and respiratory rate (C), and C5a and lactate (D) are shown. $r$ : Pearson coefficient.

Table 5. Receiver-operator curve (ROC) analyses on TAFI, C5a, leukocyte count, lactate level, heart rate, and respiratory rate at admission to the emergency department to predict the development of sepsis after polytrauma. Sensitivity and specificity are given as percentage values. Abbreviations: AUC, area under the curve and CI, confidence interval.

\begin{tabular}{|c|c|c|c|c|c|}
\hline Parameter & Cut-Off Value & $\begin{array}{c}\text { Sensitivity \% } \\
\text { (95\% CI) }\end{array}$ & $\begin{array}{c}\text { Specificity \% } \\
\text { (95\% CI) }\end{array}$ & $\operatorname{AUC}(95 \% \mathrm{CI})$ & $p$-Value \\
\hline TAFI [ng/mL] & $>54857$ & $\begin{array}{c}64.00 \\
(42.52 \text { to } 82.03)\end{array}$ & $\begin{array}{c}87.50 \\
(47.35 \text { to } 99.68)\end{array}$ & $\begin{array}{c}0.7550 \\
(0.585 \text { to } 0.925)\end{array}$ & 0.032 \\
\hline C5a [ng/mL] & $<17.00$ & $\begin{array}{c}75.00 \\
\text { (55.13 to } 89.31)\end{array}$ & $\begin{array}{c}70.00 \\
\text { (34.75 to } 93.33)\end{array}$ & $\begin{array}{c}0.7286 \\
(0.547 \text { to } 0.910)\end{array}$ & 0.034 \\
\hline leukocytes [U/nL] & $<14.50$ & $\begin{array}{c}65.63 \\
\text { (46.81 to } 81.43) \\
\end{array}$ & $\begin{array}{c}69.23 \\
\text { (38.57 to } 90.91)\end{array}$ & $\begin{array}{c}0.7043 \\
(0.527 \text { to } 0.882) \\
\end{array}$ & 0.033 \\
\hline lactate $[\mathrm{mg} / \mathrm{dL}]$ & $<28.50$ & $\begin{array}{c}78.26 \\
\text { (56.30 to } 92.54) \\
\end{array}$ & $\begin{array}{c}69.23 \\
(38.57 \text { to } 90.91)\end{array}$ & $\begin{array}{c}0.6973 \\
(0.500 \text { to } 0.895) \\
\end{array}$ & 0.052 \\
\hline heart rate & $<102.5$ & $\begin{array}{c}86.96 \\
\text { (66.41 to } 97.22)\end{array}$ & $\begin{array}{c}64.29 \\
(35.14 \text { to } 87.24)\end{array}$ & $\begin{array}{c}0.6957 \\
(0.490 \text { to } 0.902)\end{array}$ & 0.049 \\
\hline respiratory rate & $<15.00$ & $\begin{array}{c}63.64 \\
(40.66 \text { to } 82.80)\end{array}$ & $\begin{array}{c}64.29 \\
\text { (35.14 to } 87.24)\end{array}$ & $\begin{array}{c}0.7029 \\
\text { (0.511 to } 0.895)\end{array}$ & 0.043 \\
\hline
\end{tabular}

The results in Figure 5 reflect the dynamic course of both parameters after trauma and sepsis. The distribution of the TAFI and C5a values in the samples obtained in the ED and subsequent daily measurements for ten consecutive days show that the TAFI was significantly decreased on admission, day 2, and on day 9 in the sepsis group compared to the control group without sepsis $(p<0.05$; Figure 5A). On the contrary, the C5a values were significantly increased on admission, days 2-6, and on day 9 in the sepsis group compared to the control group without sepsis ( $p<0.05$; Figure $5 B$ ). 

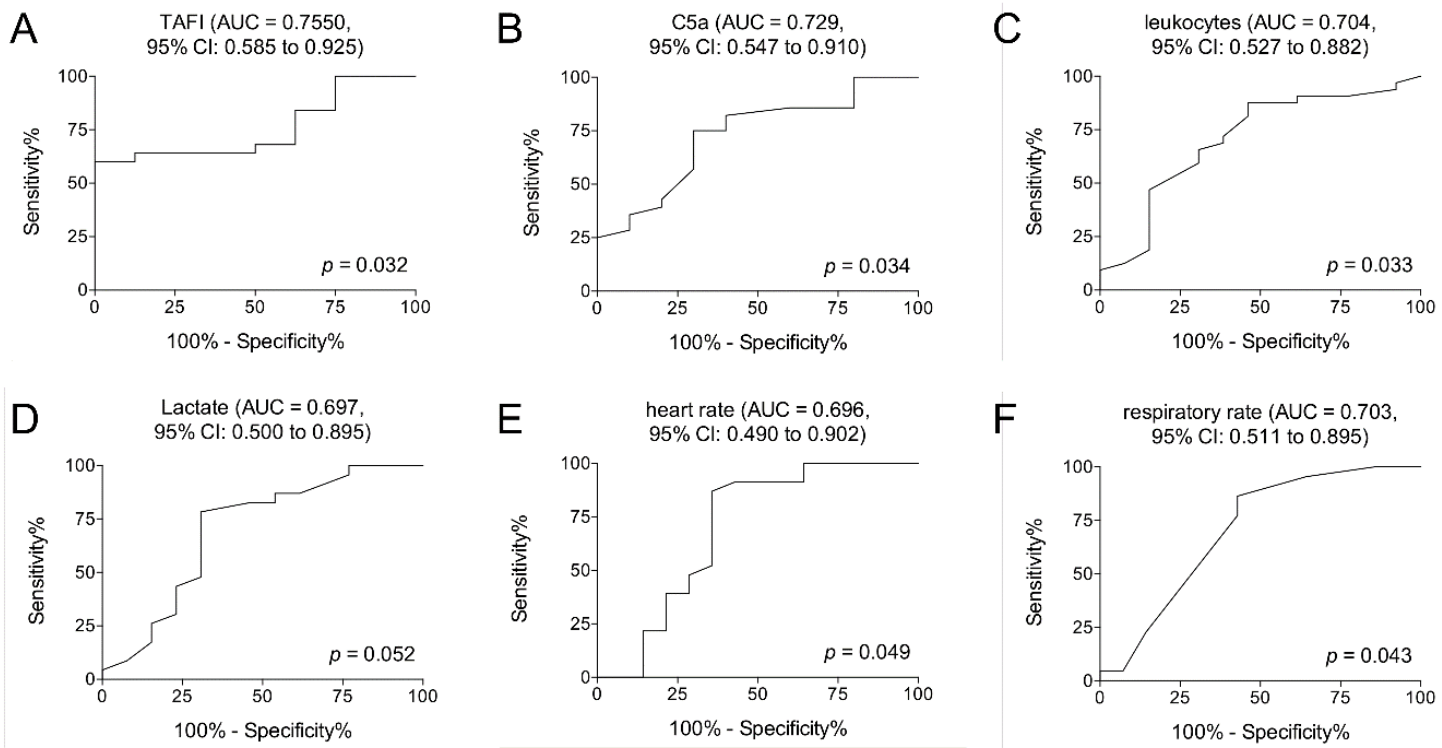

Figure 4. Receiver operating curve analyses on TAFI (A), C5a (B), leukocyte counts (C), lactate levels (D), heart rate (E), and respiratory rate (F) at admission to the emergency department to predict the development of sepsis after polytrauma are demonstrated. $p<0.05$ : statistically significant, AUC: area under the curve, and CI: confidence interval.

A

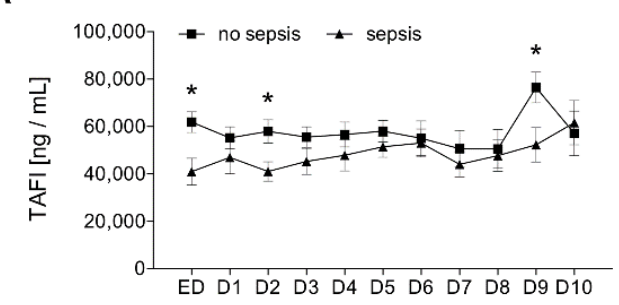

B

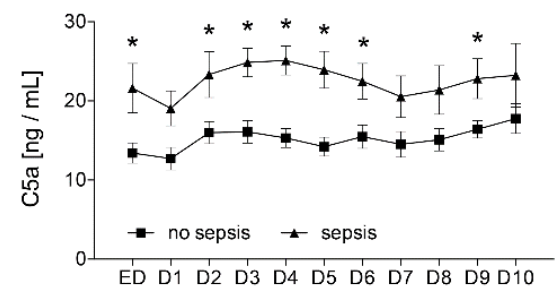

Figure 5. Upon admission of severely injured trauma patients $(n=48)$ to the emergency department (ED), plasma TAFI levels (A) and plasma C5a levels (B) were determined daily for ten days (D1-D10). Patients were stratified to those who developed sepsis in their clinical course (sepsis, $n=14$ ) vs. those who did not develop infectious complications (no sepsis, $n=34$ ). Data are shown as mean \pm SEM. ${ }^{*} p<0.05$ sepsis vs. no sepsis at the indicated time.

\section{Discussion}

Polytraumatized patients who survive the initial post-injury phase are at a serious risk to die from septic complications during their further clinical treatment [18]. Both the inflammatory/complement and the coagulation systems contribute to these harmful events. Regarding this, it is important to note that the cross-talk between the inflammation/complement and the coagulation occurs in both directions, as coagulation can affect the inflammatory activity as well as inflammation is able to activate coagulation $[14,28,29]$. TAFI is a carboxypeptidase B-like proenzyme, which, on the one hand, upon its activation to TAFIa by the thrombin-thrombomodulin complex inhibits fibrinolysis by removing C-terminal lysines from fibrin $[8,9]$. On the other hand, activated complement factors C3a and C5a can be inactivated by TAFIa $[22,30]$. The data suggests that TAFI may be a potential link between the inflammation/complement and the coagulation systems.

In the underlying study, we observed significantly reduced TAFI levels in patients developing sepsis during their clinical course after polytrauma compared to polytraumatized patients without septic complications. This difference occurred early upon admission of the patients to the ED. In contrast, C5a levels were significantly increased in septic patients after polytrauma. A significant negative 
correlation between TAFI and C5a levels was found. In addition, the correlation analyses of TAFI and C5a with the SOFA score have demonstrated a significant negative correlation of TAFI and a significant positive correlation of $\mathrm{C} 5 \mathrm{a}$ with the SOFA score. These findings enhance markedly the impact of both TAFI and C5a as biomarkers, which may indicate later-occurring development of the post-traumatic sepsis. However, whether reduced TAFI levels in septic patients after polytrauma derive from, e.g., consumption in the course of coagulopathy or whether initially reduced TAFI levels potentially put patients at risk for septic complications still remains elusive. It can be speculated that maybe upon reduced TAFI levels, missing inactivation of C3a and C5a may lead to an immunological imbalance and an excessive immunological reaction. As nicely reviewed and originally published by the expert group around Huber-Lang, anaphylatoxin C5a appears in the circulation of humans within 20 min post-polytrauma, and its levels have been related to the mortality rate [31,32]. That data indicated an almost synchronical rapid activation and dysfunction of the complement, suggesting a trauma-induced complementopathy early after injury [32]. Furthermore, the authors suggest that these events may participate in the impairment of the post-traumatic innate immune response. Within the time latency between $20 \mathrm{~min}$ of the complement activation, as shown by Huber-Lang, and $66 \mathrm{~min}$ until admission of patients to the ED, as shown in our study, certainly, a trauma-induced complementopathy may have occurred. Thus, levels of both TAFI and C5a may have been different at the onset of trauma, and we cannot exclude any alterations which may have emerged until the blood sampling in the ED was performed. Thus, the latency between the timepoint of trauma and sampling in the ED must be taken into account when interpreting the results. Relja et al. reported elevated TAFI levels in polytraumatized patients with and without infectious complications but with a significantly higher increase in both TAFI and TAFIa in patients without infectious complications [14]. This supports the hypothesis that reduced TAFI levels may increase the risk for the development of septic complications. In line with these findings, Zeerleder et al. as well reported significantly decreased TAFI levels in septic patients compared to healthy controls [33]. Interestingly, in our pilot study, we found that TAFI levels at admission to the ED and at day 4 after the trauma were significantly lower in the smaller cohort of patients with complications compared to the control group [14]. In that study, we were able to demonstrate that TAFI levels inversely correlated with the inflammation-associated development of not-further-defined complications after major trauma. Furthermore, coagulopathic patients, however, experienced significantly lower levels of activated TAFI on admission and on days six to eight [34]. Based on those results, the finding that TAFI and C5a levels immediately at admission to the ED can stratify patients who are going to develop sepsis in their clinical course is certainly a promising result in terms of a search for early sepsis biomarkers. Yet, it remains to be noted that, in our study, we did not prospectively evaluate the levels of both potential biomarkers and that this remains to be elucidated in further studies.

Naito et al. investigated the link between C5a and TAFI with regard to acute lung injury and demonstrated that, in TAFI-deficient mice, LPS treatment induced a more severe acute lung injury (ALI) compared to wild-type mice [35]. Furthermore, the authors observed significantly higher concentrations of IL-1beta, TNF-beta, and IL-6, along with increased lung infiltration of neutrophils, in TAFI-deficient mice [35]. Naito et al. concluded that TAFI plays a critical role in the pathogenesis of ALI via its ability to regulate the activity of complement factor C5a [35]. Nishimura et al. reported worse alveolitis in TAFI knock-out mice than in wild-type (WT) mice with C5a instillation directly into the lungs [36]. In line with these results, we observed decreased TAFI levels and elevated C5a levels in patients who developed septic complications after polytrauma. More importantly, TAFI correlated negatively with C5a. Fujiwara et al. investigated the role of TAFI in allergic bronchial asthma and showed significantly worse airway responsiveness and increased pulmonary concentrations of IL-5 and osteopontin in a TAFI-deficient mouse model [37]. Pretreatment with a C5a antibody significantly attenuated these effects, and thus, the authors concluded that TAFI plays a protective role in the pathogenesis of allergic inflammation, probably by inhibiting the complement system [37]. In a model of inflammatory arthritis (anticollagen antibody-induced arthritis (CAIA)), Song et al. investigated the 
role of TAFI and showed that TAFI deficiency exacerbated inflammatory arthritis and, furthermore, that the cleavage of C5a by TAFI suppressed the ability of C5a to recruit immune cells to the affected joint [38]. Interestingly, the authors showed that the expression of both TAFI and C5a in synovial fluid was higher in patients with autoimmune arthritis than in those with osteoarthritis and concluded that TAFI plays an important role in attenuating local C5a-mediated inflammation and, thus, represents a molecular link between inflammation and coagulation in autoimmune arthritis [38].

While the above-mentioned studies all unanimously reported that decreased/lower levels of TAFI led to aggravated disease severity, Mook-Kanamori et al. showed that higher protein levels of TAFI in cerebrospinal fluid were significantly associated with systemic complications in patients with bacterial meningitis [39]. The authors observed survival benefits in TAFI-deficient mice in a pneumococcal meningitis mouse model as compared to wild-type mice and concluded that, during the initial phase of infection, a low level or an absence of TAFI results in initially increased complement levels, which may improve survival (in the animal model) and reduce systemic complications in humans suffering from bacterial meningitis [39]. Taken together, it still remains elusive whether TAFI acts as an acute reactant marker that links homeostasis and inflammation or whether a lack of TAFI plays an active role in the development of septic complications after polytrauma.

Most clinical studies examining anticoagulant effects on thrombo-inflammation have been performed in the context of sepsis, although some specific examples relevant to ischemia/reperfusion injuries are also reported. Unfortunately, the data in septic patients in which inhibitors of thrombin have been applied, as well as their efficiency, are limited [40]. As an example, the overall benefit of low molecular weight heparin in patients with sepsis remains, despite considerable investigations, uncertain [40]. Although initial trials with the IV infusion to restore plasma ATIII levels were promising, larger studies did not provide any benefit for overall mortality, and consequently, Rhodes et al. have made specific recommendations against the use of ATIII in the updated International Guidelines for the Management of Sepsis and Septic Shock [40,41]. The use of other anticoagulant agents, e.g., recombinant human activated protein $C$, have failed to consistently demonstrate a reduction in 28-day all-cause mortality in clinical trials [42]. Currently, soluble recombinant human thrombomodulin (rhTM) is undergoing clinical evaluation for the treatment of severe sepsis [40]. ART-123, an rhTM, appears to be a safe intervention in critically ill sepsis patients in phase $2 \mathrm{~b}$ trials $[40,43]$.

Although this study has several limitations-of those, the most important, the limited sample size-it must be considered that there is no significant difference between demographic and trauma characteristics between evaluated groups, which certainly ensures better compatibility of assessed data. Nevertheless, it has to be taken into account that patients in the sepsis group received significantly more PRBC during the whole clinical course, while there was no significant difference within the first $24 \mathrm{~h}$ (Table 2). Sadjadi et al. reported that, in trauma patients, infection was associated with the transfusion of PRBC and that transfused patients had eight times the increased risk of infection independently of their injury severity [44]. Likewise, Claridge et al. reported a dose-dependent correlation between transfusions of PRBC and the development of infection in traumatized patients [45]. Based on the data of our study, we cannot fully exclude an effect of transfused PRBC either on TAFI or on C5a, and this remains to be elaborated in future works. Although several studies have reported that a PRBC transfusion can negatively affect clinical outcomes [46,47], it still remains unclear if TAFI is an acute phase reactant that links hemostasis and inflammation or whether it plays an active role in the development of post-traumatic sepsis. With regard to the effects of PRBC transfusions on, e.g., the complement, certain clinical syndromes such as transfusion-related acute lung injury (TRALI) and transfusion-associated circulatory overload (TACO) that occur within $6 \mathrm{~h}$ of blood transfusions indicate an association $[48,49]$. The major drivers of those complications and their pathogenesis, however, are complex and incompletely understood. The potential connection between the complement system and neutrophils is given, as well as the parallels between these syndromes and other acute pulmonary disorders, which are known for their involvement of the complement. Yet, similar to TAFI, we cannot exclude a direct impact of the PRBS transfusion on C5a levels or its activity; however, since the 
transfusion rates within the first $24 \mathrm{~h}$ after the trauma did not differ between the septic and nonseptic group, we believe that the data as demonstrated are plausible. Moreover, C5a levels remain increased in septic patients nearly throughout the complete observational period, and thus, we believe that this effect is associated with inflammatory changes caused by sepsis rather than with PRBC transfusions, which, anyway, were initially not significantly enhanced. However, the increased amount of totally transfused PRBC in our study must therefore be considered as a disturbing variable by interpreting the data. Further limitations of the study include the study setting, since this study was conducted in a single center. In addition, the heterogeneity of the traumatized patients, as well as the variable timing of measurements, must be carefully considered in data interpretation. Although there were sufficient measurements made later after the trauma to determine the roles of TAFI and C5a as indicators of sepsis, a long-term study also including septic patients from other pathologies is necessary, but this was not the aim of the study.

Early recognition and effective management of patients at risk for infectious complications are essential for improved outcomes. However, early recognition specifically of post-traumatic sepsis is impeded by the lack of clinically proven and utilized biomarkers. The current work in clinical settings has not yielded the requisite gold standards for the diagnosis and monitoring of post-traumatic sepsis. Yet, identifying patients at risk for the development of sepsis during their clinical course is of great importance for further clinical treatment. TAFI and C5a may be helpful, specifically in, e.g., decision-making about the timing for post-traumatic surgeries or indicate patients that should early receive antibiotic therapy or undergo further specific clinical tests of sepsis markers. With regard to complement factors or TAFI as potential biomarkers in general, clinical studies with large subject numbers are needed to obtain the complete temporal profiles of, e.g., activation of the complement factors or factor dynamics in the course of sepsis development. Presumably, this should provide a multipanel set of biomarkers, which can be coupled with routine lab tests and blood cultures for the diagnosis and monitoring of sepsis.

Taken together, in the underlying study, we were able to show that the development of sepsis after major trauma is associated with decreased TAFI levels and increased C5a levels. The significant negative correlation between TAFI and C5a supports the concept that reduced TAFI levels may lead to an exacerbation of septic complications and that TAFI might play a protective role by downregulating inflammation. Furthermore, irrespective of their possible pathomechanistical roles in the onset of sepsis, both TAFI and C5a might serve as very early diagnostic markers to detect patients at risk for the development of sepsis or septic complications.

Author Contributions: Conceptualization, B.R. and T.L.; methodology, J.T.V. and B.R.; formal analysis, A.H. and B.R.; investigation, J.T.V.; data curation, B.R.; writing-original draft preparation, J.T.V.; writing-review and editing, I.M., A.H., T.L., and B.R.; visualization, A.H. and B.R.; supervision, B.R.; and project administration, B.R. All authors have read and agreed to the published version of the manuscript.

Funding: This research received no external funding.

Acknowledgments: We thank Kerstin Wilhelm, Minhong Wang, and Alexander Schaible for their outstanding technical assistance.

Conflicts of Interest: The authors declare no conflict of interest.

\section{References}

1. Norton, R.; Kobusingye, O. Injuries. N. Engl. J. Med. 2013, 368, 1723-1730. [CrossRef]

2. Osborn, T.M.; Tracy, J.K.; Dunne, J.R.; Pasquale, M.; Napolitano, L.M. Epidemiology of sepsis in patients with traumatic injury. Crit. Care Med. 2004, 32, 2234-2240. [CrossRef]

3. Relja, B.; Land, W.G. Damage-associated molecular patterns in trauma. Eur. J. Trauma Emerg. Surg. 2019, 1-25. [CrossRef]

4. Relja, B.; Mors, K.; Marzi, I. Danger signals in trauma. Eur. J. Trauma Emerg. Surg. 2018, 44, $301-316$. [CrossRef] 
5. Nast-Kolb, D.; Aufmkolk, M.; Rucholtz, S.; Obertacke, U.; Waydhas, C. Multiple organ failure still a major cause of morbidity but not mortality in blunt multiple trauma. J. Trauma 2001, 51, 835-841, discussion 41-2. [CrossRef]

6. Markiewski, M.M.; DeAngelis, R.A.; Lambris, J.D. Complexity of complement activation in sepsis. J. Cell Mol. Med. 2008, 12, 2245-2254. [CrossRef]

7. Ward, P.A. The harmful role of c5a on innate immunity in sepsis. J. Innate Immun. 2010, 2, 439-445. [CrossRef]

8. Foley, J.H.; Kim, P.Y.; Mutch, N.J.; Gils, A. Insights into thrombin activatable fibrinolysis inhibitor function and regulation. J. Thromb. Haemost. 2013, 11 (Suppl. 1), 306-315.

9. Bouma, B.N.; Mosnier, L.O. Thrombin activatable fibrinolysis inhibitor (TAFI) at the interface between coagulation and fibrinolysis. Pathophysiol. Haemost. Thromb. 2003, 33, 375-381. [CrossRef]

10. Muto, Y.; Suzuki, K.; Iida, H.; Sakakibara, S.; Kato, E.; Itoh, F.; Kakui, N.; Ishii, H. EF6265, a novel inhibitor of activated thrombin-activatable fibrinolysis inhibitor, protects against sepsis-induced organ dysfunction in rats. Crit. Care Med. 2009, 37, 1744-1749. [CrossRef]

11. Ravindranath, T.M.; Goto, M.; Demir, M.; Tobu, M.; Kujawski, M.F.; Hoppensteadt, D.; Samonte, V.; Iqbal, O.; Sayeed, M.M.; Fareed, J. Tissue factor pathway inhibitor and thrombin activatable fibrinolytic inhibitor plasma levels following burn and septic injuries in rats. Clin. Appl Thromb. Hemost. 2004, 10, 379-385. [CrossRef]

12. Verbon, A.; Meijers, J.C.; Spek, C.A.; Hack, C.E.; Pribble, J.P.; Turner, T.; Dekkers, P.E.; Axtelle, T.; Levi, M.; van Deventer, S.J.; et al. Effects of IC14, an anti-CD14 antibody, on coagulation and fibrinolysis during low-grade endotoxemia in humans. J. Infect. Dis. 2003, 187, 55-61. [CrossRef]

13. Watanabe, R.; Wada, H.; Watanabe, Y.; Sakakura, M.; Nakasaki, T.; Mori, Y.; Nishikawa, M.; Gabazza, E.C.; Nobori, T.; Shiku, H. Activity and antigen levels of thrombin-activatable fibrinolysis inhibitor in plasma of patients with disseminated intravascular coagulation. Thromb. Res. 2001, 104, 1-6. [CrossRef]

14. Relja, B.; Lustenberger, T.; Puttkammer, B.; Jakob, H.; Morser, J.; Gabazza, E.C.; Takei, Y.; Marzi, I. Thrombin-activatable fibrinolysis inhibitor (TAFI) is enhanced in major trauma patients without infectious complications. Immunobiology 2013, 218, 470-476. [CrossRef]

15. Ricklin, D.; Hajishengallis, G.; Yang, K.; Lambris, J.D. Complement: A key system for immune surveillance and homeostasis. Nat. Immunol. 2010, 11, 785-797. [CrossRef]

16. Ajona, D.; Ortiz-Espinosa, S.; Pio, R. Complement anaphylatoxins C3a and C5a: Emerging roles in cancer progression and treatment. Semin. Cell Dev. Biol. 2019, 85, 153-163. [CrossRef]

17. Blatt, A.Z.; Saggu, G.; Kulkarni, K.V.; Cortes, C.; Thurman, J.M.; Ricklin, D.; Lambris, J.D.; Valenzuela, J.G.; Ferreira, V.P. Properdin-Mediated C5a Production Enhances Stable Binding of Platelets to Granulocytes in Human Whole Blood. J. Immunol. 2016, 196, 4671-4680. [CrossRef]

18. Satyam, A.; Graef, E.R.; Lapchak, P.H.; Tsokos, M.G.; Dalle Lucca, J.J.; Tsokos, G.C. Complement and coagulation cascades in trauma. Acute Med. Surg. 2019, 6, 329-335. [CrossRef]

19. Guo, R.F.; Ward, P.A. Role of C5a in inflammatory responses. Ann. Rev. Immunol. 2005, 23, 821-852. [CrossRef]

20. Clarke, A.R.; Christophe, B.R.; Khahera, A.; Sim, J.L.; Connolly, E.S., Jr. Therapeutic Modulation of the Complement Cascade in Stroke. Front. Immunol. 2019, 10, 1723. [CrossRef]

21. Keshari, R.S.; Silasi, R.; Popescu, N.I.; Patel, M.M.; Chaaban, H.; Lupu, C.; Coggeshall, K.M.; Mollnes, T.E.; DeMarco, S.J.; Lupu, F. Inhibition of complement C5 protects against organ failure and reduces mortality in a baboon model of Escherichia coli sepsis. Proc. Natl. Acad. Sci. USA 2017, 114, E6390-E6399. [CrossRef]

22. Declerck, P.J. Thrombin activatable fibrinolysis inhibitor. Hamostaseologie 2011, 31, 165-166;168-173. [CrossRef]

23. Hugenholtz, G.C.; Meijers, J.C.; Adelmeijer, J.; Porte, R.J.; Lisman, T. TAFI deficiency promotes liver damage in murine models of liver failure through defective down-regulation of hepatic inflammation. Thromb. Haemost. 2013, 109, 948-955. [CrossRef]

24. Eguchi, A.; Franz, N.; Kobayashi, Y.; Iwasa, M.; Wagner, N.; Hildebrand, F.; Takei, Y.; Marzi, I.; Relja, B. Circulating Extracellular Vesicles and Their miR “Barcode” Differentiate Alcohol Drinkers with Liver Injury and Those Without Liver Injury in Severe Trauma Patients. Front. Med. 2019, 6, 30. [CrossRef]

25. Calandra, T.; Cohen, J. International Sepsis Forum Definition of Infection in the ICUCC. The international sepsis forum consensus conference on definitions of infection in the intensive care unit. Crit. Care Med. 2005, 33, 1538-1548. [CrossRef] 
26. Shankar-Hari, M.; Phillips, G.S.; Levy, M.L.; Seymour, C.W.; Liu, V.X.; Deutschman, C.S.; Angus, D.C.; Rubenfeld, G.D.; Singer, M.; Sepsis Definitions Task, F. Developing a New Definition and Assessing New Clinical Criteria for Septic Shock: For the Third International Consensus Definitions for Sepsis and Septic Shock (Sepsis-3). JAMA 2016, 315, 775-787. [CrossRef]

27. Singer, M.; Deutschman, C.S.; Seymour, C.W.; Shankar-Hari, M.; Annane, D.; Bauer, M.; Bellomo, R.; Bernard, G.R.; Chiche, J.D.; Coopersmith, C.M.; et al. The Third International Consensus Definitions for Sepsis and Septic Shock (Sepsis-3). JAMA 2016, 315, 801-810. [CrossRef]

28. Levi, M.; Nieuwdorp, M.; van der Poll, T.; Stroes, E. Metabolic modulation of inflammation-induced activation of coagulation. Semin. Thromb. Hemost. 2008, 34, 26-32. [CrossRef]

29. Okamoto, T.; Tanigami, H.; Suzuki, K.; Shimaoka, M. Thrombomodulin: A bifunctional modulator of inflammation and coagulation in sepsis. Crit. Care Res. Pract. 2012, 2012, 614545. [CrossRef]

30. Myles, T.; Nishimura, T.; Yun, T.H.; Nagashima, M.; Morser, J.; Patterson, A.J.; Pearl, R.G.; Leung, L.L. Thrombin activatable fibrinolysis inhibitor, a potential regulator of vascular inflammation. J. Biol. Chem. 2003, 278, 51059-51067. [CrossRef]

31. Chakraborty, S.; Karasu, E.; Huber-Lang, M. Complement After Trauma: Suturing Innate and Adaptive Immunity. Front. Immunol. 2018, 9, 2050. [CrossRef] [PubMed]

32. Burk, A.M.; Martin, M.; Flierl, M.A.; Rittirsch, D.; Helm, M.; Lampl, L.; Bruckner, U.; Stahl, G.L.; Blom, A.M.; Perl, M.; et al. Early complementopathy after multiple injuries in humans. Shock 2012, 37, 348-354. [CrossRef] [PubMed]

33. Zeerleder, S.; Schroeder, V.; Hack, C.E.; Kohler, H.P.; Wuillemin, W.A. TAFI and PAI-1 levels in human sepsis. Thromb. Res. 2006, 118, 205-212. [CrossRef] [PubMed]

34. Lustenberger, T.; Relja, B.; Puttkammer, B.; Gabazza, E.C.; Geiger, E.; Takei, Y.; Morser, J.; Marzi, I. Activated thrombin-activatable fibrinolysis inhibitor (TAFIa) levels are decreased in patients with trauma-induced coagulopathy. Thromb. Res. 2013, 131, e26-e30. [CrossRef]

35. Naito, M.; Taguchi, O.; Kobayashi, T.; Takagi, T.; D’Alessandro-Gabazza, C.N.; Matsushima, Y.; Boveda-Ruiz, D.; Gil-Bernabe, P.; Matsumoto, T.; Chelakkot-Govindalayathil, A.L.; et al. Thrombin-activatable fibrinolysis inhibitor protects against acute lung injury by inhibiting the complement system. Am. J. Respir. Cell Mol. Biol. 2013, 49, 646-653. [CrossRef]

36. Nishimura, T.; Myles, T.; Piliponsky, A.M.; Kao, P.N.; Berry, G.J.; Leung, L.L. Thrombin-activatable procarboxypeptidase B regulates activated complement C5a in vivo. Blood 2007, 109, 1992-1997. [CrossRef]

37. Fujiwara, A.; Taguchi, O.; Takagi, T.; D’Alessandro-Gabazza, C.N.; Boveda-Ruiz, D.; Toda, M.; Yasukawa, A.; Matsushima, Y.; Miyake, Y.; Kobayashi, H.; et al. Role of thrombin-activatable fibrinolysis inhibitor in allergic bronchial asthma. Lung 2012, 190, 189-198. [CrossRef]

38. Song, J.J.; Hwang, I.; Cho, K.H.; Garcia, M.A.; Kim, A.J.; Wang, T.H.; Lindstrom, T.M.; Lee, A.T.; Nishimura, T.; Zhao, L.; et al. Plasma carboxypeptidase B downregulates inflammatory responses in autoimmune arthritis. J. Clin. Investig. 2011, 121, 3517-3527. [CrossRef]

39. Mook-Kanamori, B.B.; Valls Seron, M.; Geldhoff, M.; Havik, S.R.; van der Ende, A.; Baas, F.; van der Poll, T.; Meijers, J.C.; Morgan, B.P.; Brouwer, M.C.; et al. Thrombin-activatable fibrinolysis inhibitor influences disease severity in humans and mice with pneumococcal meningitis. J. Thromb. Haemost. 2015, 13, $2076-2086$. [CrossRef]

40. Jackson, S.P.; Darbousset, R.; Schoenwaelder, S.M. Thromboinflammation: Challenges of therapeutically targeting coagulation and other host defense mechanisms. Blood 2019, 133, 906-918. [CrossRef]

41. Rhodes, A.; Evans, L.E.; Alhazzani, W.; Levy, M.M.; Antonelli, M.; Ferrer, R.; Kumar, A.; Sevransky, J.E.; Sprung, C.L.; Nunnally, M.E.; et al. Surviving Sepsis Campaign: International Guidelines for Management of Sepsis and Septic Shock: 2016. Intensive Care Med. 2017, 43, 304-377. [CrossRef] [PubMed]

42. Bernard, G.R.; Vincent, J.L.; Laterre, P.F.; LaRosa, S.P.; Dhainaut, J.F.; Lopez-Rodriguez, A.; Steingrub, J.S.; Garber, G.E.; Helterbrand, J.D.; Ely, E.W.; et al. Efficacy and safety of recombinant human activated protein C for severe sepsis. N. Engl. J. Med. 2001, 344, 699-709. [CrossRef] [PubMed]

43. Vincent, J.L.; Ramesh, M.K.; Ernest, D.; LaRosa, S.P.; Pachl, J.; Aikawa, N.; Hoste, E.; Levy, H.; Hirman, J.; Levi, M.; et al. A randomized, double-blind, placebo-controlled, Phase $2 \mathrm{~b}$ study to evaluate the safety and efficacy of recombinant human soluble thrombomodulin, ART-123, in patients with sepsis and suspected disseminated intravascular coagulation. Crit. Care Med. 2013, 41, 2069-2079. [CrossRef] [PubMed] 
44. Sadjadi, J.; Cureton, E.L.; Twomey, P.; Victorino, G.P. Transfusion, not just injury severity, leads to posttrauma infection: A matched cohort study. Am. Surg. 2009, 75, 307-312. [PubMed]

45. Claridge, J.A.; Sawyer, R.G.; Schulman, A.M.; McLemore, E.C.; Young, J.S. Blood transfusions correlate with infections in trauma patients in a dose-dependent manner. Am. Surg. 2002, 68, 566-572. [PubMed]

46. Taylor, R.W.; O’Brien, J.; Trottier, S.J.; Manganaro, L.; Cytron, M.; Lesko, M.F.; Arnzen, K.; Cappadoro, C.; $\mathrm{Fu}, \mathrm{M}$.; Plisco, M.S.; et al. Red blood cell transfusions and nosocomial infections in critically ill patients. Crit. Care Med. 2006, 34, 2302-2308, quiz 9. [CrossRef]

47. Patel, S.V.; Kidane, B.; Klingel, M.; Parry, N. Risks associated with red blood cell transfusion in the trauma population, a meta-analysis. Injury 2014, 45, 1522-1533. [CrossRef]

48. Jongerius, I.; Porcelijn, L.; van Beek, A.E.; Semple, J.W.; van der Schoot, C.E.; Vlaar, A.P.J.; Kapur, R. The Role of Complement in Transfusion-Related Acute Lung Injury. Trans. Med. Rev. 2019, 33, 236-242. [CrossRef]

49. Semple, J.W.; Rebetz, J.; Kapur, R. Transfusion-associated circulatory overload and transfusion-related acute lung injury. Blood 2019, 133, 1840-1853. [CrossRef]

(C) 2020 by the authors. Licensee MDPI, Basel, Switzerland. This article is an open access article distributed under the terms and conditions of the Creative Commons Attribution (CC BY) license (http://creativecommons.org/licenses/by/4.0/). 